\title{
Cuestionar la práctica investigativa: experiencias colaborativas en dos regiones en México
}

\author{
Questioning the research practice: collaborative experiences \\ in two regions in Mexico
}

\author{
Gloria Lara Millán \\ Universidad Michoacana de San Nicolás de Hidalgo \\ aram.gloria@gmail.com (MÉXICO) \\ PráXedes Muñoz SÁNCHez \\ Universidad Católica de Murcia \\ pmunoz@ucam.edu (ESPAÑA)
}

Recibido: 07.032018

Aceptado:29.05.2019

\section{RESUMEN}

En este artículo se analizan algunas de las dificultades que en la práctica de investigación se han identificado en dos espacios rurales en los estados de Oaxaca y Tabasco en México, y se exponen los múltiples desafíos que el investigador debe afrontar, especialmente en relación con los conceptos de colaboración e intervención durante el trabajo que realiza. Si bien este se basa en tareas específicas de indagación y colaboración, suele haber acciones de desarrollo ajenas al entorno comunitario, que incluso no son clara o conscientemente percibidas por los actores protagonistas. Es así que el objetivo de esta presentación es reflexionar sobre la práctica investigativa colaborativa, exponiendo los aciertos y desaciertos del proceso. El concepto de intervención social se asocia con el de investigación colaborativa, en tanto que ambos pretenden poner en el centro de la participación a los sujetos, sin embargo es necesario delimitar las implicaciones de cada uno de estos conceptos en los casos estudiados. En este texto se describen aspectos teóricos y metodológicos acerca de la intervención social y la investigación colaborativa con enfoque en derechos humanos, y se reflexiona en torno al proceso de acompañamiento y las decisiones que se adoptan durante la investigación, así como acerca de la experiencia del diálogo con los colectivos con los que se colabora para construir conocimiento. 


\title{
PALABRAS CLAVE
}

Investigación colaborativa, intervención social, derechos humanos, México.

\begin{abstract}
This work analyzes some difficulties found in the practice of collaborative research in rural areas in Mexico, each with its historical peculiarities and passed through the application of public policies or economic policies. The researcher's activist participation has multiple advantages in that it applies development concepts outside the community environment that are sometimes not reflected by the protagonist actors. The objective of the text is to reflect on the collaborative research practice, exposing the successes and failures of the process and the challenges to overcome. As part of the research experience, the concept of social intervention is discussed, which is associated with collaborative research, in the center of participation is understood by the subjects. In this text are described the concepts and methodological aspects raised by the specialists in the subject of social intervention, then associate it with collaborative research with a human rights approach. The two collaborative research experiences focussed are described, and we reflect on the accompaniment process and the reflections on the decisions regarding the objectives, methodology and results, as well as the experience of the dialogue with the collectives with the collaboration for knowledge.
\end{abstract}

\section{KEY WORDS}

Collaborative research, social intervention, human rights, Mexico.

\section{INTRODUCCIÓN}

Este trabajo expone el análisis de dos casos de investigación en espacios rurales en México, en los estados de Tabasco y Oaxaca, donde se examinan las acciones que durante la práctica de la investigación tienen relación con los conceptos y acciones de colaboración y, en su caso, de intervención social. Siendo partícipe de una práctica antropológica, el investigador, en sus tareas toma un papel activo y utiliza metodologías colaborativas desde una perspectiva de derechos humanos. Sin embargo, dicha metodología frecuentemente se auxilia de modelos de intervención utilizados en otras disciplinas sociales ${ }^{1}$, los cuales de manera general están encaminados a solucionar problemas o impulsar proyectos de desarrollo comunitario en búsqueda de la transformación social. Esto parece

${ }^{1}$ Dichos modelos han sido desarrollados de manera sistemática y perfeccionados por profesionales de trabajo social; el concepto se precisará más adelante. 
generar un conflicto o implica dificultades en el proceso de investigación, las cuales analizaremos en este trabajo.

La participación activista del investigador, como hemos comprobado, tiene múltiples desafíos, en tanto que se trata de un acompañamiento donde existen varios riesgos. Entre estos podemos incluir los siguientes: a) tomar el lugar de los actores comunitarios protagonistas de la transformación; b) la liberación de responsabilidades en la toma de decisiones, en tanto se asumen en conjunto con los actores comunitarios; c) tener un peso decisivo en el conjunto de decisiones, en tanto que el profesional posee un conjunto de conocimientos legitimados por instituciones académicas y d) dificultades para superar la relación vertical que supone la intervención social, en tanto esta parte de un conocimiento que aplica "el experto", bajo conceptos de desarrollo ajenos al entorno comunitario o que no sean reflexionados por los actores protagonistas.

El objetivo de este trabajo es reflexionar sobre la práctica investigativa colaborativa, exponiendo los aciertos y desaciertos que se observan en el proceso y los desafíos por superar en este campo. Como parte de la experiencia investigativa se pone a discusión el concepto de intervención social, el cual se asocia con el de investigación colaborativa, entendiendo que ambos forman parte de la práctica de investigación y pretenden poner en el centro de la participación a los actores protagonistas de la transformación. Pensamos que la utilidad del texto se centra en el cuestionamiento de la orientación de acciones durante la práctica de investigación, sea en el sentido de colaboración o intervención, lo cual tiene repercusiones importantes en la relación y expectativas de los sujetos que son acompañados y cuyas luchas sociales por la justicia, equidad, desarrollo y derechos humanos continúan en sus comunidades.

La presentación de este trabajo se divide en tres partes. En la primera se describen conceptos y aspectos metodológicos que plantean especialistas en el tema de la intervención social, y se discute la relación de ese concepto con la investigación colaborativa con enfoque de los derechos humanos. En la segunda parte se presentan las dos experiencias de investigación colaborativa que examinamos, una en el estado de Tabasco y la otra en el estado de Oaxaca. En el mismo apartado se trata acerca de las preocupaciones manifiestas por los actores durante la colaboración-intervención de las investigadoras. De manera general se describe asimismo el espacio, sus actores y el momento histórico en el que surge la colaboración investigativa, así como la manera en que cada investigadora realiza su práctica en los acompañamientos de los procesos organizativos de los grupos y comunidades en las regiones en cuestión. Finalmente, en la tercera parte se reflexiona en torno al proceso de acompañamiento realizado y sobre las decisiones en torno a los objetivos, metodología y resultados de las labores investigativas, así como en torno de la experiencia del diálogo con los colectivos con los que colaboramos para construir conocimiento.

La descripción de cada investigación, realizada de forma individual, consideró el trabajo etnográfico, entendido como "una descripción de una cultura, de una sociedad o de procesos sociales y culturales" (Reygadas, 2014:92), en un espacio y tiempo determinado. Se describen también las actividades de co- 
laboración solicitadas por los grupos comunitarios o colectivos y las voces de los actores aparecen en las reflexiones que hacen en torno los problemas que les aquejan o las demandas específicas derivadas de algún conflicto. Además de estos momentos, se recogieron opiniones obtenidas a través de conversaciones y entrevistas con algunos de los miembros de los colectivos sociales con los que se estuvo participando en las actividades desarrolladas.

El trabajo de campo de ambas experiencias de investigación en el sur de México muestra dos casos en regiones pluriétnicas, cuyas preocupaciones convergen en que ambas vivían y siguen viviendo situaciones de injusticia social, despojo de recursos naturales y en uno de los casos demandas de acceso a recursos públicos articuladas con la pertenencia identitaria.

La idea es cuestionar la forma en que se da la práctica de intervención social en campo y los múltiples errores que se cometen en el proceso, en ocasiones por falta de experiencia o previsión de modificaciones que se producen en la orientación de las actividades, y cuando es necesario ajustarlas de acuerdo con sus objetivos iniciales. En algunas ocasiones esto puede ser explicado por el desconocimiento del entorno social en el que se está actuando, y en otras es necesario reflexionar con mayor detenimiento en las repercusiones políticas que implica la toma de decisiones en el proceso. Asimismo, se observó que este exige una mayor minuciosidad en la formulación del objetivo tanto como en la revisión o expectativas de resultados a largo plazo que implican la intervención. De manera relevante es también necesario poner atención en el diálogo intercultural descolonizador del saber ${ }^{2}$ y finalmente buscar una mayor claridad en el uso de herramientas conceptuales y metodológicas en el campo. Esperamos que este análisis de la práctica pueda ser un ejercicio útil no sólo para mejorar el trabajo futuro propio, sino también el de otros profesionistas interesados en el tema.

\section{LA INTERVENCIÓN SOCIAL}

La intención de este apartado es reflexionar sobre los conceptos, metodologías y características de la investigación colaborativa asociada a la intervención social, cuyos modelos son frecuentemente instrumentados no sólo en la academia, sino también por organizaciones civiles que trabajan en comunidades rurales en México ${ }^{3}$. Esta asociación es posible porque la investigación colaborativa

\footnotetext{
${ }^{2}$ El diálogo intercultural descolonizador, parafraseando a Catherine Walsh (2005:45) se refiere a las relaciones e intercambios culturales que buscan ser equitativos entre pueblos, personas, conocimientos y prácticas culturales. Dicha interacción es compleja, en tanto parte del conflicto inherente en las asimetrías sociales, económicas y de poder en las comunidades. En la interrelación siempre están presentes los sistemas, las estructuras y tales relaciones de poder que posicionan y diferencian a grupos, lenguas, prácticas y conocimientos.

${ }^{3}$ La Investigación Acción Participativa frecuentemente es instrumentada por organizaciones de la sociedad civil, en gran medida se considera como una metodología popular, emancipadora y transformadora, cuya referencia cercana para el caso de Latinoamérica es Paulo Freire y Fals Borda. Esta metodología ha sido difundida en los espacios rurales a través de canales académi-
} 
es declaradamente activista e intervencionista, en tanto que busca el cambio social (Speed, 2006:81).

De manera general, los modelos que conceptualizan la intervención social proponen metodologías encaminadas a mejorar las condiciones de vida y buscar la transformación social. Entre ellas se encuentran proyectos de diferente índole: participación social para resolver conflictos al interior de alguna comunidad o grupo social, impulsar proyectos de desarrollo comunitario, procesos de repolitización, de asimilación cultural y/o intervenciones que modelan la participación social e institucional.

La intervención social ha sido conceptualizada desde diferentes visiones en los trabajos de investigación en ciencias sociales y los relacionadas con la salud humana. En el proceso de intervención se combinan una o más metodologías, estas en ocasiones son identificadas como proyectos de investigación-acción, labor activista, trabajo disciplinar o actividad académico-militante. En la mayor parte de este tipo de procesos de intervención, los propósitos a mediano o largo plazo del trabajo propuesto contemplan la transformación ${ }^{4}$ social o desencadenar procesos de desarrollo.

Maritza Montero (2012) observa que la discusión acerca del concepto de intervención en varias disciplinas académicas muestra una tensión persistente, en tanto ese concepto se percibe de diferentes formas: como un conjunto de acciones de naturaleza unilateral, asistencialista, algunas de esas incorporando saberes externos e internos, y otras con la transformación social como objetivo final, entre otras consideraciones. La misma autora señala que hay dos formas de intervenir en un grupo social o comunitario: aquella cuya transformación proviene "desde abajo", impulsada por los actores o la comunidad y aquella que proviene "desde arriba", impulsada por el Estado a través de las políticas públicas.

Desde la psicología comunitaria, se han desarrollado propuestas que toman varios enfoques analíticos como el psicoanálisis, sobre todo en aquellas cuestiones relacionadas con derechos humanos y conflictos bélicos. Manuel A. Moreno (2012), refiriéndose al contexto colombiano, expone casos clínicos a través de los cuales trata de entender las dinámicas comunitarias y sugiere la necesidad de conocer en profundidad los casos antes de intervenir. También desde la psicología, particularmente para el caso de Latinoamérica se desarrolló desde mediados de siglo XX la intervención participativa-comprometida, en la que se destaca la educación popular de Paulo Freire y la sociología crítica de Fals Borda. Actualmente "la intervención como es usada en la psicología comunitaria basada en la praxis es entendida como la acción conjunta de dos tipos de agentes de transformación y de conocimiento (Montero, 2012:70).

cos, organizaciones civiles que promueven la educación popular y crítica. Algunas métodos son la evaluación rural participativa, talleres de acción participante, observación participante, video participante, metodologías indígenas, entre otras.

${ }^{4}$ Por ejemplo, en la disciplina de trabajo social según el momento histórico en que revisemos el significado de "transformación" miraremos algunas tendencias a las que se refiere Gianinna Muñoz (2015: 422) al "normalizar, adaptar o higienizar, como educar, politizar, liberar o emancipar", estos cambios que han formado parte de la razón del existir profesional. 
La Investigación Acción Participante (IAP, cuyo término fue propuesto en 1944 por (Lewin, 2006:15) se originó como una especie de "voz disidente" en la academia. Su objetivo era "ligar el enfoque experimental de la ciencia social con programas de acción social que respondieran a los problemas sociales principales" La IAP pretendía hacer partícipes a los sujetos en la misma investigación, como intervención social favorecedora del desarrollo comunitario.

Esther Wiesenfeld (2014:10) considera que la Investigación Acción Participativa, cuyo modelo implica asimismo el compromiso del investigador y su participación activa, favorece la construcción de conocimiento: "contribuir a construir conocimientos relevantes a los problemas que le atañen y a modificar las condiciones que los suscitaron (...) es indispensable", pero la dificultad que observa es la distancia que se crea "entre discurso y acción, de lo teórico, a lo metodológico".

En el ámbito de la antropología aplicada, la intervención social se vincula a la participación del profesional con las poblaciones más vulnerables y aquellas que padecen exclusión social en diversos ámbitos donde se producen dificultades de modelos aplicables (Villalón, 2012). El contexto de esa intervención está relacionado con aspectos de discriminación (por género, etnia, religión, preferencia sexual, etcétera), racismo, pobreza, explotación, violencia, migración, entre muchas otras problemáticas sociales. En esta disciplina se insiste en dar voz a los participantes, protagonistas de transformación, trascendiendo la relación investigador-informante. Sin embargo, el proceso de intervención social en las praxis supuestamente transformadoras, pueden derivar en prácticas autoritarias y unilaterales. Muñoz (2015) pone especial atención en dar la voz a los excluidos y oprimidos, asumiendo que el conocimiento de los actores es tan valioso como el que produce la academia .

Para dar atención a la voz de los sujetos protagonistas de la transformación se plantea el concepto de la investigación colaborativa (véase Rappaport y Ramos 2005; Leyva y Speed, 2008), esta fue entendida como un diálogo de saberes en un diálogo intercultural (Dietz, 2012; Vitón, 2013) en el que se negocia la prioridad de un determinado discurso político (reflejando una demanda, exigencia o petición), que deriva en la construcción de objetivos, estrategias y metodologías acordes a las necesidades de los colectivos. En el diálogo referido existe una colaboración interpretativa por parte de la comunidad, y en ese diálogo se recopilan datos, pero también se profundiza en los significados de los actores/ la comunidad. En palabras de Rappaport y Ramos (2005:34): "La colaboración necesariamente implica una apertura a diferentes formas de pensar, de formular preguntas de investigación y análisis político".

En síntesis, si los procesos de intervención social apuntan a la transformación desde los actores y colectivos, éstos supondrían el intercambio mutuo de conocimientos y definiciones de proyectos únicos, en tanto responden a su propia historicidad. Es así que no existe un modelo de intervención universal, aunque en ocasiones se pretendan aplicar "modelos exitosos". En lo que convergen los modelos es en la aspiración a la transformación social, la aportación de 
soluciones a los problemas sociales, la búsqueda de justicia social y respeto por los derechos humanos.

$\mathrm{Al}$ respecto de la lucha de los derechos humanos cada vez forma parte de los discursos de lucha de diversas comunidades y colectivos. Una de las peculiaridades observadas en las políticas multiculturales implementadas desde la década de 1990 en los Estados nacionales es la internacionalización de la retórica de la diversidad como derecho humano y valor (Briones, 2005:11). Desde finales del siglo XX, los derechos humanos forman parte de un discurso globalizado que sostiene demandas de justicia social e igualdad y, también de las medidas de presión internacional para posibilitar cierto tipo de estabilidad social en los Estados Nación. Tal como lo afirma Speed (2006:76) este discurso junto con la implementación de mecanismos de democracia liberal globalizaron los derechos humanos, en un mundo en el que el cambio social ya no cruzaba por los proyectos ideológicos del socialismo o el comunismo.

Especialistas críticos en el tema legal (Brown y Haley, 2002:24 citado en Speed, 2006) argumentan que las prerrogativas legales son marcos regulatorios de las conductas e incluso pueden coptar las demandas más radicales. En esta lógica los autores llaman la atención en reflexionar con atención las metas de corto plazo que se fijan en las luchas y demandas sociales, ya que pueden formar marcos opresores, en tanto fijan culturas e identidades asociadas a los derechos. Este análisis crítico debería estar siempre presente en la investigación y el activismo.

Sin duda los principios universales en los que se sostienen los derechos humanos, cuestionan de qué manera se incluye la diversidad cultural y los conocimientos de saberes que no están legitimados por instituciones académicas o científicas. Existen múltiples brechas para establecer un pluralismo jurídico en el país, sin embargo, hasta ahora son base para luchar por el derecho de los pueblos indígenas y afrodescendientes en el contexto de la expansión de los marcos jurídicos para resolver problemas políticos y sociales en ausencia de estado de derecho y falta de democracia 5 .

Sousa (2014) identifica que una de las problemáticas sociales es que los derechos humanos son concebidos como monoculturales. Sin embargo, a decir de Laclau (1985:46) "lo universal emerge de lo particular, no como un principio que fundamenta y explica lo particular, sino como un horizonte incompleto que sutura la identidad particular dislocada". Esto supone una relación distinta entre lo particular y lo universal, en cuya lógica las identidades no están totalmente separadas, ni lo universal cancela todas las diferencias. Es en esta fisura en la que la apropiación de las herramientas jurídicas de derechos humanos nacionales e internacionales forman parte de la estrategia política de los colectivos para desarrollar mecanismos de defensa ante la expoliación y agravio en sus contextos,

${ }^{5}$ García, M. (2014:176) menciona que el derecho como herramienta de acción política por parte de movimientos sociales y grupos políticos ha crecido de manera importante desde finales del siglo XX, y esto se observa en tendencias como la independencia judicial, el constitucionalismo militante, la incorporación del Derecho Internacional de los Derechos humanos y la difusión de la cultura de la legalidad, cuatro fenómenos que afirma ilustran la juridización política. 
así como el derecho a la diferencia cultural y la proyección de un desarrollo cuya concepción alude a la historicidad de los pueblos.

Los instrumentos jurídicos de los derechos humanos constituyen herramientas útiles para actuar políticamente en entornos en los que la expoliación de recursos naturales, la corrupción institucional y la violencia a la población no sólo es continua, sino además opera al amparo de diferentes niveles de gobiernos en México.

La experiencia colaborativa con organizaciones y asociaciones civiles en los estados de Oaxaca y Tabasco en diferentes años en lo que va del siglo XXI que se expone a continuación muestra una parte de nuestro trabajo etnográfico y problematización de cuestiones que se dieron en el mismo proceso de la investigación y formaron parte de la reflexión en torno a la colaboración- intervención.

\section{EXPERIENCIA DE INVESTIGACIÓN EN LA COSTA CHICA DE OAXACA}

El primer caso de intervención social se ubica en la Costa Chica en el Pacífico sur, perteneciente al estado de Oaxaca. Se trata de un espacio continuo sobre la franja costera del Océano Pacífico en los estados de Guerrero y Oaxaca. Sus límites geográficos, siguiendo el parámetro orográfico, se asientan en la franja costera entre el puerto de Acapulco, en el estado de Guerrero, y Santa María Huatulco, en el estado de Oaxaca. Sobre este espacio se hallan extensiones de planicie, sabana y lomeríos donde coexisten importantes cuencas hidrológicas. Las actividades económicas a las que fundamentalmente se dedica la población son la agricultura, ganadería, pesca y comercio. Para quienes viven en espacios cercanos a las playas, las actividades incluyen la oferta de servicios turísticos por temporadas. De manera específica, dentro de esta región enfocamos una pequeña micro-región frontera (Distrito) ${ }^{6}$, situada en el Estado de Oaxaca y colindante con el estado de Guerrero, cuyo espacio central es el municipio de Santiago Pinotepa Nacional (véase Mapa 1). El Distrito ubicado en la región de Costa ${ }^{7}$ tiene el nombre de Santiago Jamiltepec. En este lugar habita población indígena, afromexicana y mestiza. La Asociación Civil Comisión Regional de los Derechos Humanos de la Costa (CRDHC), a cuyo trabajo institucional se dedicará el análisis, se encuentra en Pinotepa, uno de los espacios urbanos más importantes en el estado de la Oaxaca y con alta concentración poblacional.

La entidad oaxaqueña es una de las más rezagadas en el país: registra alrededor de $67 \%$ de personas viviendo en condición de pobreza. En la región costera también se reportan enormes desventajas sociales para sus habitantes, situación que les impide el disfrute de derechos básicos como salud, alimentación, educa-

${ }^{6}$ La legislación político-administrativa del estado de Oaxaca establece los ámbitos jurisdiccionales y de competencias en diferentes niveles: estatal, regional, distrital, municipal y local. Hay notable dispersión y atomización de localidades, en su mayor parte consideradas rurales.

${ }^{7}$ La Costa es la tercera región más poblada en la entidad. 
ción, vivienda y acceso a los medios de producción. De manera general existe gran diversidad natural y un amplio mosaico cultural en la población por los intensos flujos de migración en la región, con la circulación de prácticas culturales diversas. Poco más de la tercera parte de la población en la entidad habla una lengua indígena (CDI, 2015) y la mayor concentración de población afromexicana se encuentra en la Costa ${ }^{8}$.

La colaboración con la asociación civil Comisión Regional de Derechos Humanos de la Costa (CRDHC) se suscribe en un proyecto realizado por la organización a favor del conocimiento de los derechos humanos, el ejercicio ciudadano y la democracia. El proyecto de la CRDHC fue parte de un proceso de formación más amplio de algunos miembros del equipo desde finales de la década de 1990. La asociación civil se creó en 1992, en el contexto de desmantelamiento de instituciones y programas gubernamentales de apoyo a las actividades productivas de campesinos en el país.

En la década de 1990 hubo transformaciones sociopolíticas que fueron un marco político y referente para las luchas por el reconocimiento de derechos ciudadanos y culturales en México. Unas orientadas a la descentralización del país y otras al reconocimiento de la diferencia cultural. Entre estos cambios se apunta la diversificación de actores sociales y organizaciones en la esfera pública y el fortalecimiento de instancias locales y regionales (Lara, 2007). Estos cambios estuvieron asociados a políticas neoliberales tendientes a la reducción del Estado y la descentralización pública, mismas que acrecentaron la brecha de desigualdad social. En este contexto emergieron diversos colectivos que reivindicaron identidades colectivas para abrir espacios de participación, defender proyectos y hallar alternativas propias de desarrollo para insertarse en el mundo global. De manera particular, en la Costa Chica, como en múltiples lugares de México, el autoritarismo, el control caciquil, la corrupción, la violencia y el control de medios de comunicación eran y siguen siendo la práctica cotidiana.

"La Comisión Regional de Derechos Humanos de la Costa, A.C. permite hablar de los derechos que tiene la gente; llegamos en los momentos donde la tortura y la represión era el pan de cada día, mucha gente era castigada y encarcelada de manera injusta"9.

Las y los integrantes de la CRDHC en su mayoría vivían en el municipio de Pinotepa Nacional y sus perfiles educativos eran diversos, así como sus profesiones o empleos. Eran mujeres y hombres, algunos dedicados a la enseñanza de educación básica, en oficios técnicos, el trabajo en el campo y estudiantes. Al interior de las comunidades participaban de manera muy activa las mujeres, mu-

${ }^{8}$ En cuanto a la población afromexicana, la Encuesta Intercensal realizada por el Instituto Nacional de Estadística y Geografía (INEGI) mostró que en el estado de Oaxaca se identifican como afromexicanos alrededor de $4.9 \%$ de la población total, misma se concentra en su mayor parte en la región de la Costa Oaxaqueña (CDI, 2015)

9 Entrevista con Néstor Ruíz Hernández, presidente y fundador de la CRDHC. Pinotepa Nacional. Febrero 2002. 
chas de ellas con liderazgo y capacidad organizativa destacada; sin embargo no ocupan cargos de decisión dentro de la organización. Algunos de sus integrantes se adscribían como indígenas, no así la identificación afromexicana, la cual tomó fuerza de forma paulatina, a la par de la construcción de un discurso regional que actualmente está creciendo y reivindicándose.

El trabajo regional en la defensa de los derechos humanos y ciudadanos articulaba básicamente tres líneas de acción: apoyo en la defensa jurídica de los derechos humanos; talleres de educación para los derechos humanos y gestoría social, esta última dedicada a realizar proyectos para impulsar las actividades del campo o mejorar las condiciones de vida en las comunidades. Los problemas de las comunidades que se presentaban al colectivo eran numerosos, y se relacionaban con el abuso de autoridades gubernamentales, despojo de tierras por parte de particulares, violación a sus derechos humanos, discriminación en algún servicio, actos de violencia o amenaza o la necesidad de gestionar medios que impulsaran sus actividades productivas o les proporcionaran beneficios inmediatos. $\mathrm{La}$ Costa, como espacio pluricultural, requirió de la defensa de derechos culturales, cuestión que trabajó la asociación civil de manera paulatina, en sintonía con el discurso multicultural gubernamental implementado desde la década de $1990^{10}$.

Las personas o colectivos atendidos por la asociación se dedicaban en su mayoría a la agricultura, y sus condiciones socioeconómicas exponían regularmente escasos medios de producción y carencia de servicios públicos tanto educativos como de salud. En menor medida, acudían algunas autoridades municipales y locales en busca de información y orientación para gestionar recursos o entender la forma de aplicación de recursos públicos que llegaban al municipio. Las reformas realizadas a la institución municipal por el gobierno federal en 1983 y en los años subsecuentes hicieron posible que los gobiernos municipales administraran y distribuyeran sus recursos al interior de las comunidades y definieran reglamentaciones en su espacio local.

En este tiempo el tema de democracia era resonante al interior del país y del interés en este participaban varias organizaciones nacionales y locales, entre ellas el Movimiento Ciudadano por la Democracia, AC, el Centro de Servicios Municipales, A.C., y la Escuela Municipalista de Oaxaca, organizada por Servicios para una Educación Alternativa (EDUCA, AC).

${ }^{10}$ En el caso de mexicanos, en 1992 y 2001 se hicieron cambios a la Constitución nacional relativos al reconocimiento de la diversidad cultural. En 1992, México se definía como nación multiétnica y pluricultural y en el año 2001, el llamado gobierno de la alternancia aprobó la reforma sobre derechos y cultura indígena. 


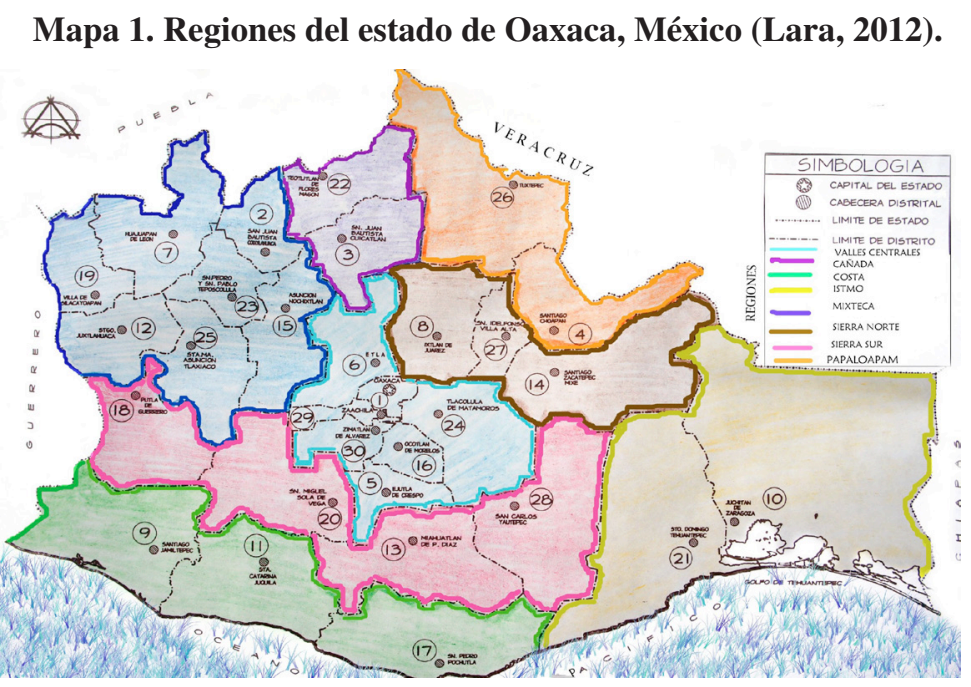

El proyecto de la CRDHC citado tenía un peso político relevante en la región debido al ejercicio autoritario de los gobiernos y políticos locales, condición que se sigue reproduciendo en varias de las regiones del país, aunque este se ha transformado y adaptado al mercado y a las regulaciones que se establecen a nivel global y local, aun cuando en ocasiones se añaden contrapesos y se fortalecen los monopolios e inversiones de los grupos de poder.

El contexto de inicio del siglo XXI era prometedor en el país, pues los resultados de las elecciones en México llevaron al Partido Acción Nacional (PAN) a la presidencia, después de poco que más de 70 años en el poder de gobiernos del Partido Revolucionario Institucional (PRI). Este cambio de partido fue esperanzador, parecía avizorar el cambio próximo en los gobiernos estatales, muchos de los cuales estaban en manos del PRI (Lara, 2018).

Con el propósito de reflexionar en torno al ejercicio ciudadano, se hicieron varias estancias de colaboración con la CRDHC. En este caso analizado, únicamente se abordan dos momentos, que corresponden a los años 2002 y 2012. Estos dos momentos son útiles para la descripción, en tanto que en el primero, la transición del poder era una aspiración, y entonces se creía que el cambio de partido en el gobierno en el estado cambiaría favorablemente las relaciones con los municipios ${ }^{11}$. En el segundo momento, el cambio de partido en el gobierno estatal se hizo posible; sin embargo, de forma similar a lo que ocurrió a nivel federal en el año 2000, el cambio de partido no mejoró las relaciones con los

${ }^{11}$ Actualmente el país está conformado por 32 entidades federativas o estados. El presidente de la República es electo cada seis años, así como los gobernadores de cada estado. El nivel local de gobierno es el municipio. En Oaxaca existen 570 municipios; 152 eligen sus autoridades por el sistema de partidos y 418 por el sistema de usos y costumbres. En el país existen 67 lenguas indígenas, en Oaxaca se reconocen a 18 grupos etnolinguísticos y las poblaciones afromexicanas. 
municipios y tampoco se tradujo en un cambio significativo y de mayor bienestar para la población oaxaqueña.

\title{
3.1. Los momentos de intervención-colaboración en la Costa
}

Como parte de sus actividades mensuales, la CRDHC organiza talleres para la educación y formación de los derechos humanos y la democracia. La educación popular, que involucraba la aplicación de técnicas participativas, ${ }^{12}$ ha sido parte importante de la formación de varios integrantes de esta asociación civil. Entre los principales temas abordados y promovidos como base de las actividades de la CRDHC se encuentran el derecho a la información, la transparencia, la distribución de recursos públicos y vigilancia de su uso, así como el conocimiento de funciones y atribuciones de las autoridades. Todos estos conceptos se vinculan al trabajo de la organización tomando como enfoque un marco de fortalecimiento deseable de la sociedad civil. La participación de hombres y mujeres en las asambleas comunitarias de la CRDHC se considera indispensable, en tanto son instancias de decisión y vigilancia de los recursos públicos.

La impartición de talleres son fundamentales para socializar los temas que son propósito del trabajo de la CRDHC. Muestra de ello son los realizados en la región. De manera general, en los talleres realizados en varias comunidades de la Costa se describió el contenido básico de la Ley que mandata la distribución de recursos públicos en los municipios y se hizo énfasis en la participación activa de población en las comunidades para su conocimiento y vigilancia, entendiendo que la participación es un ejercicio ciudadano, así como el derecho al goce de estos recursos.

\section{Cuadro 1. Las estrategias de la Asociación Civil en los talleres}

\begin{abstract}
Temas
Democratizar la información de la cuenta pública

Conocimiento de la cantidad otorgada cada año por el gobierno federal a cada municipio, las reglas básicas de adminis-

Contenido básico tración, la asignación de recursos (partidas o rubros) en los que se puede invertir y la necesaria participación de la comunidad para definir el tipo de desarrollo al que aspiran.

Preguntas para
introducir la discu-
sión en el tema

¿Quién(es) decide(n) cómo se distribuyen los recursos públicos en mi comunidad? ¿Cómo participo en las decisiones de desarrollo de mi comunidad?
\end{abstract}

${ }^{12} \mathrm{El}$ uso de las técnicas participativas para la educación popular se refiere a herramientas de apoyo en procesos de organización y concientización en las comunidades (Bustillos y Vargas, 1993). 


\section{Método \\ Convocatoria abierta en asamblea comunitaria, y realización de trabajo en equipos para anotar en papelógrafo las partici- paciones.}

Técnicas Juegos de integración grupal y de trabajo en equipo

\section{Cuadro 2. Relatos derivados del ejercicio de reflexión y discusión grupal en el taller de recursos públicos y participación ciudadana}

\begin{abstract}
¿Quién(es) deciden cómo se distribuyen los recursos públicos en mi comunidad?

"Los políticos locales, ¿quién más?”.

"Una vez que está en la silla el presidente se manda solo. Ya no nos toma en cuenta".
\end{abstract}

"Si las autoridades comunitarias son del mismo partido, sí lo consideran a uno".

"Hay mucho robo por parte del gobierno municipal, se llenan las bolsas en el cargo".

"El dinero sólo le toca a la gente de su partido, además en la cabecera municipal se queda la mayor parte de los recursos; a las comunidades les dan lo que sobra".

\section{¿Cómo participo en las decisiones de desarrollo de mi comunidad?}

"Hay apatía. En muchas ocasiones no participo".

"Si participo, mi opinión no es tomada en cuenta".

"Aquí tiene voz solo la gente señalada (con prestigio económico y político). Y si no se parece nuestra opinión a la suya, entonces hay que callarse".

"Casi todos tienen que participar en comités. Trabajamos en nuestra comunidad, tal vez no todos de forma equitativa".

"Es la lucha de siempre, pero sí es necesario estar presentes. Luego nos tachan de pleitistas, pero no hay otra forma. Yo siempre ando participando en los comités"

Fuente: Sistematización de ejercicios grupales en los talleres de recursos públicos y participación ciudadana en el distrito de Jamiltepec, Oaxaca. 2001-2002. Elaboración propia del cuadro sinóptico

Pasados ocho años en el año 2012, las líneas de acción para la CRDHC se transformaron. El tema de la transición democrática parecía ser entonces un asunto superado a nivel federal, pues dos gobiernos del PAN habían sido electos de forma consecutiva y se había establecido una institución cuya función estaba dedicada a la transparencia del uso de los recursos públicos. También a nivel estatal, con el cambio de partido en el poder en la gubernatura de Oaxaca por primera vez la administración estaba en manos de una coalición de partidos que le ganó al PRI. Entre las líneas de acción de la asociación civil se encontraban con ello la defensa jurídica de los derechos humanos, el impulso de la participa- 
ción ciudadana y la gestión social. La primera de estas líneas de trabajo estaba a cargo de los abogados que participaban en la CRDHC, y las otras dos del equipo operativo en las comunidades, que se ocupaba de impulsar la participación ciudadana en las asambleas municipales. En estas se definían a su vez las formas de inversión de recursos públicos y los mecanismos de vigilancia de su aplicación, así como la formación de autoridades municipales y la gestión social. Las dos últimas líneas de acción eran apoyadas también por la organización de Enlace de Pueblos, Organizaciones y Comunidades de la Costa Autónomas, AC (EPOCA).

En ese momento el cambio tecnológico era inminente. La mayor parte de los trámites se hacían por medio de las web institucionales y la comunicación en redes sociales formó parte de un ejercicio de información constante. Las formas de negociación con las instituciones del Estado para gestionar recursos iba cambiando en ese decurso, de modo que se establecieron reglamentaciones en la Ley Federal de Fomento de las Organizaciones de la Sociedad Civil en el año 2004. Los nuevos requerimientos obligaron a tener una figura legal, profesionalizarse para responder cuestiones que exigían las reglas de operación de cada programa gubernamental, y en algunos casos era necesario contratar de manera temporal recursos humanos en las organizaciones que respondieran a dichos requisitos. Las nuevas dinámicas institucionales aumentaron, sin embargo, la incertidumbre en torno de la generación de ingresos suficiente y multiplicaron la preocupación por la sobrevivencia institucional y personal.

En el transcurso de unos cuantos años cambiaron así las dinámicas de participación, apoyo y solidaridad, que no abordaremos, pero que sin duda forman parte de las respuestas de participación en las comunidades. En tanto, el tema de participación ciudadana siguió siendo central en la agenda de acciones de la asociación. El contexto de pobreza, falta de oportunidades y empleo no mostraba cambios significativos en la región. Sin embargo, la emergencia novedosa fue la reivindicación afrodescendiente, que tomó mayor fuerza en el siglo XXI en el contexto de la declaración de Naciones Unidas (en 2011) y de alguna forma favorable para los pobladores de la Costa Chica, en tanto que su presencia en esta región es de las más numerosas en el país ${ }^{13}$. En los cuadros del Anexo 2 puede observarse el contenido este aspecto al observar el contenido de uno de los ejercicios grupales en torno a la participación ciudadana y la organización comunitaria.

${ }^{13}$ Según datos de la Encuesta Intercensal del año 2015, a nivel nacional se calcula que $1.3 \%$ de la población se identifica como afrodescendiente, es decir, alrededor de 1'381,853 de personas. Esta población se encuentra dispersa en varias entidades y existen concentraciones mayores a cien mil habitantes en los estados de México, Veracruz, Guerrero, Oaxaca y Ciudad de México. 


\section{Cuadro 3. Las estrategias de la AC en los talleres}
Temas
Participación ciudadana y organización comunitaria

\author{
Contenido básico
}
Preguntas para introducir la discu- sión en el tema
Método
Técnicas
Reflexionar en torno a las formas de organización comunita- ria, la intervención de recursos públicos y la participación en la toma de decisiones
¿De qué manera se organiza la comunidad?, ¿Cómo se parti- cipa dentro de las decisiones comunitarias y en qué se invier- ten los recursos públicos asignados al municipio?
Convocatoria abierta en asamblea comunitaria, realización de trabajo en equipos para anotar en papelógrafo el contenido de las participaciones
Juegos de integración grupal y de trabajo en equipo

\section{Cuadro 4. Ejercicio grupal tema participación ciudadana y formas de organización comunitaria en el distrito de Jamiltepec, Oaxaca.}

\section{¿De qué manera se organiza la comunidad?}

Para trabajar se cita a reunión. En la comunidad se trabaja por comités. Quien tiene hijos en la escuela, sabe que en algún momento va a servir. Así con todos los comités, de la fiesta, del agua o de alguna obra para que se vigile que se haga. Eso es la costumbre.

La asamblea es donde se toman decisiones importantes. No toda la gente asiste, a veces las peleas empiezan con los partidos políticos y las autoridades también dividen porque a veces hacen sentir a la gente que uno está arrimado.

La gente mayor tenía más respeto en la comunidad, por lo menos nos tomaban en cuenta para pedir opinión.

La asamblea es la costumbre. Desde que me acuerdo aquí en estos pueblos es así. Ahora se habla de que somos negros, pero eso es nuevo. No se niega que haiga(sic), pero ni el gobierno ni gente le hacia caso a eso.

\section{¿Cómo participo dentro de las decisiones de mi comunidad?, ¿En qué se invierten los recursos públicos que llegan al municipio?}

La gente participa poco, está muy desconfiada. Hay mucha apatía y a la mejor cansancio. El que es autoridad se acuerda de uno cuando pide el voto, ya después se llena las bolsas de dinero y se olvida de la gente. Uno no es tonto. Y pues sí se opina sobre las obras, pero nadie trabaja si no hay dinero.

Creo que ya nos acostumbramos a eso.

Sí participamos para opinar en las obras. Lo que hay son muchas necesidades y poco dinero. La gente también da a veces lo que no tiene o no da. No hay trabajo. No hay con qué.

Se participa, cuando se puede se vigila y pregunta uno que se hace del dinero. Pero pocas veces nos dan cuentas, empezando por el presidente municipal, que da su informe, pero para saber si es cierto. Hay muchas mañas y mañosos.

Fuente: Sistematización de ejercicios grupales en el tema "participación ciudadana"; distrito de Jamiltepec, 2012. Elaboración propia. 


\subsubsection{Una lectura de la intervención del caso}

Enfocando el modelo de intervención de la CRDHC en el que se colaboró, centraremos la reflexión en torno a dos cuestiones. 1) La primera compete a la construcción de significados de los conceptos de ciudadanía, democracia y participación ciudadana. La intervención puso a disposición la información en términos de expresión de las leyes o de la políticas públicas establecidas, sin conocer cómo se han construido estas definiciones históricamente en las comunidades. Es decir, no se formuló un diálogo entre la experiencia y el conocimiento cotidiano con la Ley, de forma que se provocara la reflexión para comprender cómo se vinculan cultural y políticamente la Ley y el ejercicio ciudadano. Con esto la dirección de la intervención del equipo de la CRDHC (incluyendo a la investigadora), fue tal que se anuló el conocimiento de los intervenidos.

Lo que se obtuvo en ambos talleres fueron las respuestas de los participantes que muestran la experiencia con respecto al ejercicio ciudadano, sin hacer reflexión acerca de aspectos como el autoritarismo de los gobiernos, la exclusión centrada a pertenencias partidarias, la inequidad, la corrupción tolerada o las formas de negociación entre autoridades y ciudadanos. En el segundo taller, no obstante, se muestran de manera continuada las experiencias de exclusión, corrupción y autoritarismo, además del aumento de la desconfianza al tiempo de observarse la disminución de la solidaridad. La discusión acerca de la discriminación, que anteriormente era oculta en torno a la identificación afrodescendiente, emerge en estos años con la reivindicación por un proceso de movilización etnopolítica en la Costa Chica de los estados de Oaxaca y Guerrero. La reflexión era importante para analizar e interpretar la experiencia intercultural que posibilitara definir las prioridades para las comunidades y actuar en consecuencia. En la experiencia de Rappaport y Ramos (2005:40) el diálogo intercultural colaborativo tendría que intentar "desarrollar dispositivos conceptuales (teorizaciones) originados en las culturas nativas, que facilitaran nuevas interpretaciones consonantes con las epistemologías y prioridades políticas de las organizaciones".

El diseño de intervención tenía, sin embargo, objetivos muy acotados (ver cuadro 1 y 3), a nivel informativo básicamente. Cabe indicar que en la dinámica del taller hubo una participación nutrida, respetuosa y de escucha atenta, pero el ejercicio fue insuficiente para el diálogo intercultural para que se pudiera actuar y transformar el entorno social.

2) La segunda cuestión es la necesidad de entender la experiencia a la luz de la historia y el contexto sociopolítico locales vinculados a lo global. La discusión aporta reflexiones en torno a las rutas de acción de las instituciones gubernamentales y el marco jurídico de derechos humanos que actualmente es un resquicio para desarollar las luchas de los pueblos. Por ejemplo, el análisis de la aplicación de los instrumentos jurídicos de derechos humanos tiene varios puntos de análisis, uno que compete a los acuerdos firmados a nivel internacional y que tienen obligatoriedad según la Constitución mexicana ${ }^{14}$. Finalmente, es

${ }^{14}$ En el artículo 133 de la Constitución de los Estados Unidos Mexicanos se menciona: "Esta 
necesario comprender que "lo jurídico no solo es la ley" (Schuler, 1987, citada en Facio, 1992) ${ }^{15}$.

\subsection{El estudio de caso en Tabasco, México}

Tabasco es una región donde vive población indígena yokotan, también denominada chontal, y mestiza. En este caso destacan las acciones de resistencia y de búsqueda de justicia social, en un contexto de explotación petrolera por empresas estatales y transnacionales en las propias tierras de la población tabasqueña. A lo anterior se suman los efectos de las explotaciones marítimas en la vida de los pescadores del Golfo de México (Zalik, 2009 y Muñoz, 2012). Se afirma que este territorio, junto con sus habitantes, ha experimentado una "modernización forzada" (en términos expuestos por Tudela, 1989 y Uribe, 2003), cuyas consecuencias se observan en los procesos de descampesinización, el asistencialismo exacerbado, el clientelismo político, además de los problemas de alcohol ${ }^{16}$ y violencia, entre otros.

Tabasco es una región con bastante territorio pantanoso. Es el Estado con más disponibilidad de agua de México gracias al caudal de los ríos Grijalva y Usumacinta, procedentes de Chiapas.

El desarrollo de la capital del Estado, Villahermosa, en la ribera del río, contrasta con un mal manejo en el funcionamiento de las presas de Chiapas (la de Malpaso y Peñitas, las cuales conducen las aguas a la planicie de Tabasco). A pesar de muchos de los proyectos realizados, en planeación y gestión de recursos hídricos, se requieren soluciones integrales y la revisión del uso de las presas y caudales es sumamente importante, tanto respecto de las infraestructuras como del mantenimiento de bordos y espigones (como refieren Gracia y Fuentes, 2005). La politización del uso y manejo de las escorrentías de los ríos se ha

Constitución, las leyes del Congreso de la Unión que emanen de ella y todos los tratados que estén de acuerdo con la misma, celebrados y que se celebren por el Presidente de la República, con aprobación del Senado, serán la ley suprema de toda la Unión. Los jueces de cada estado se arreglarán a dicha Constitución, leyes y tratados, a pesar de las disposiciones en contrario que pueda haber en las constituciones o leyes de los estados". Para mayor referencia de la discusión al respecto véase Santos, M. A. (2012).

${ }^{15}$ Recordando las propuestas de Alda Facio (1992) en torno a que la ley tiene instrumentaciones en donde se sitúan operaciones fallidas y concepciones culturales que inciden sobre la operación y la apropiación de la Ley.

${ }^{16}$ El problema del alcohol deriva de la modernización acelerada. La población entrevistada recuerda como en el inicio de la urbanización de la capital del estado, Villahermosa fue cuna de las empresas petroleras, oficinas y desarrollo urbanístico en la ubicación de Pemex así como de otras empresas americanas. La población indígena y campesina aportaba la mano de obra y de ser población del sector primario pasó al secundario y terciario, lo que derivó en nuevas cotidianidades: muchos hombres cambiaron las dinámicas de las comunidades indígenas, como vivir fuera de la comunidad, disponer de dinero, emborracharse el día del cobro, quedarse tumbado en la calle y como consecuencia, pasar por arresto carcelario (información de talleres con mujeres de Tapotzingo, Tabasco) 
recrudecido a la fecha, y la propia población campesina e indígena asume que, según sea el activismo político de las comunidades, serán las represalias del gobierno del estado en la derivación de las aguas ${ }^{17}$. Un número elevado de quejas y solicitudes en los Archivos Históricos del Agua en la ciudad de México, así como para la evaluación de las indemnizaciones por el uso de los terrenos (Sandré Osorio 2009 en Álvarez y Tuñón, 2016), reflejan parte de esa problemática.

Otra de las características de Tabasco es la riqueza que tiene de recursos naturales, petróleo y gas, en su mayoría en la región de la Chontalpa (véase Mapa 2). Durante el siglo XX estos recursos han estado en proceso de apropiación por Pemex (Petróleos Mexicanos) y otras empresas trasnacionales a quienes se les vendía antes el petróleo. Lo anterior ha fomentado una mayor subalternización laboral y creado dependencia con las petroleras (Uribe 2003), además de que ante las expropiaciones de tierra los campesinos se vieron obligados a ceder para que se instalaran las tuberías de gas. Esto generó protestas sociales por un sinfín de actividades que repercutieron en las condiciones de las comunidades, tanto en aspectos ambientales y económicos como de la seguridad ciudadana (Pinkus y Contreras, 2012).

Ante este escenario, a finales de la década de 1980 surgieron movimientos sociales en Tabasco, los cuales emergieron casi al mismo tiempo que el nacimiento del Partido Revolucionario Democrático (PRD) y el llamado Pacto Ribereño, un ejemplo de estrategias gubernamentales para eliminar el activismo ambientalista que surgió contra las explotaciones petroleras, la creación de gaseoductos y la extracción de gas. Fue así que hubo protestas colectivas del campesinado y grupos ejidales de la Chontalpa, de 1976 a 1982. Posteriormente, tras las protestas de la ciudadanía, hubo indemnizaciones, que fueron identificadas como "las migajas de Pemex" (Velázquez, 1982).

Es importante anotar que los modos de vida en la región fueron transformados como fruto de las explotaciones petroleras, las formas de organización social e institucional y la productividad del Estado, que de ser un territorio que tenía una agricultura y ganadería favorable, pasó a ocuparse en la explotación petrolera (Velázquez, 1982). En este contexto desde finales de la década de 1980 se hizo notorio el liderazgo de un personaje, Andrés Manuel López Obrador, hoy conocido a nivel nacional y actual presidente del gobierno. El carismático líder tenía la confianza de las poblaciones de la región, pues se acercó a las comunidades donde las afectaciones por Pemex eran de gran relevancia y promovió mejoras en la ganadería, vivienda, entre otras cosas. Fue conocido por su poder de convocatoria, su "complejo de mesías", y como un político de "carácter peligroso" y potenciador del miedo, según lo calificaron algunos medios (Gutiérrez, 2007:45).

El liderazgo que consiguió López Obrador se consolidó al ser nombrado delegado del Instituto Nacional Indigenista durante su labor en el gobierno del PRI. Ocupó ese puesto hasta 1982. Era una figura avasallante, pues generaba grandes

17 Información trabajada Información trabajada en la etnografía. Talleres en Tamulté de la Sabana 
expectativas de cambio y tras los problemas de corrupción con el gobierno del país y la unificación de partidos de izquierdas, protagonizó su liderazgo en Tabasco con el PRD (Partido Revolucionario Democrático) en 1989 (Rivera, 2011). Después de contender dos veces como candidato a la presidencia, en 2006 y 2012, y tras sospechas de fraude electoral en la última elección, fue denominado: «líder carismático, presidente nacional, jefe de gobierno y candidato presidencial", al mismo tiempo en que el PRD fue considerado el partido con más líderes carismáticos y asociado como parte de la identidad política de su liderazgo (Navarrete, 2016).

Desde el origen del PRD, algunos municipios de la Chontalpa ganaron frente al gobierno presidencial de Tabasco, el PRI (Partido Revolucionario Institucional). Tabasco fue el único estado con mayor apoyo al PRD desde 1994 (Cedeña del Olmo, 1995).

Mapa 2. Estado de Tabasco, sureste de México, región Chontal, yokot'an (Muñoz y Cruz, 2013).

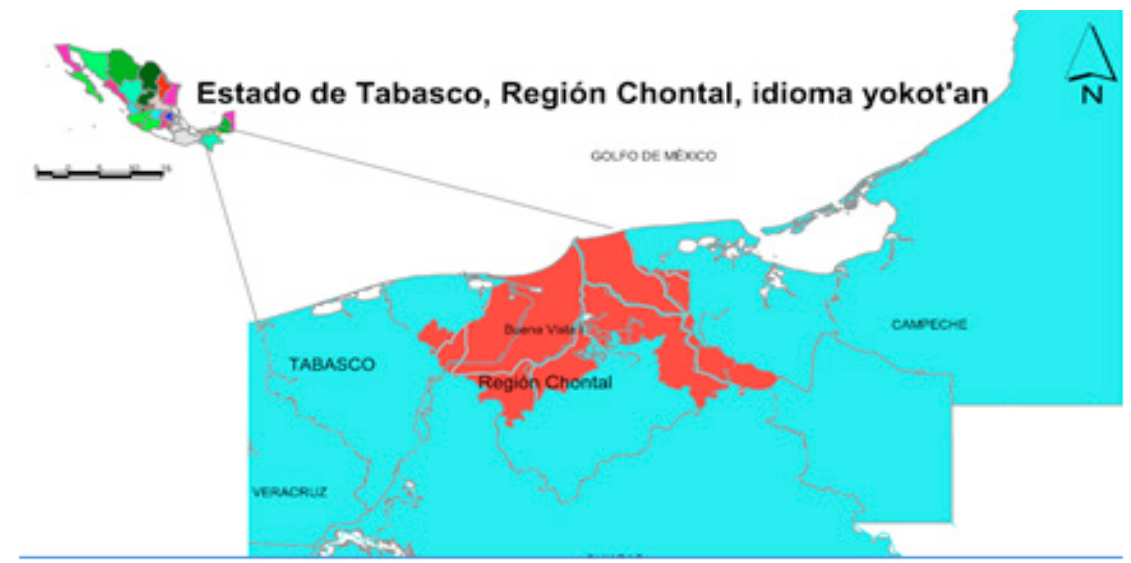

En la Chontalpa confluían acciones de colectivos de diferente carácter: cívicas, religiosas y espirituales, entre algunas otras emprendidas por los partidos políticos, en un ambiente de activismo social que fue fruto del pacto ribereño y los movimientos surgidos por las dinámicas económicas dadas desde la mitad del siglo XX, así como militantes del PRD (Muñoz, 2016). La fluidez de recursos en la región era notoria al tiempo de institucionalizarse los fideicomisos y percibirse las bonanzas por la explotación del petróleo. La abundancia de recursos creó grandes esperanzas de mejoras sociales para el pueblo tabasqueño entre campesinos, indígenas (zoques, choles y chontales), la población urbana, sindicatos, iglesias, ONG y asociaciones civiles en los distintos sectores. En este clímax, los colectivos estaban en un esplendor no visto desde entonces, con una destacada participación de los sectores populares, y del sector de la iglesia, con los jesuitas y las misioneras del Sagrado Corazón de Jesús. La población indígena fue asu- 
miendo también el activismo que se ha podido observar en las reivindicaciones de pueblos hasta el día de hoy, en acciones como la resistencia al pago de la luz, promovidas por la comunidad Tamulté de la Sabana y las protestas tras inundaciones. A esas se suman la apuesta por acciones emancipatorias confluentes con proyectos de espiritualidad maya y actividades por la defensa de los derechos humanos (Muñoz y Cruz, 2013; Muñoz, 2016).

\subsubsection{Etnografía reflexiva colaborativa en Tabasco}

Las actividades de etnografía reflexiva realizadas entre 2008 y 2015, en periodos intermitentes y acompañando a los colectivos, posibilitaron desarrollar un trabajo de investigación acción e intervención comunitaria. Las cinco organizaciones con las que se colaboró son las siguientes:

- Mujeres artesanas yokotan'ab chontales de Tapotzingo.

- Centro de estudios superior bilingüe: Centro Tecnológico de Buena Vista I, de Tamulté de la Sabana.

- Pescadores de La Barra de San Pedro.

- Pastoral Social Indígena Ik'naskinjha ${ }^{18}$ : cho'ol, chontal, tzotzil y zoque. ${ }^{19}$

- Sector de mujeres de la Asociación Ecológica Santo Tomás y Red Municipalista de Tabasco.

Durante las labores de investigación, el método etnográfico constituyó la forma de encuentro con el conocimiento ${ }^{20}$. En la perspectiva de abordaje confluyen la investigación colaborativa y la antropología comprometida, propuesta desarrollada por Hale (2008), Xóchitl Leyva y Shannon Speed (2008) y Vitón (2013). Se trabajó así para entender los saberes desde las propias comunidades, tomando en cuenta los que Robertson (1992) denomina glocalismos, entendidos como las dinámicas mundiales en las dinámicas locales.

$\mathrm{n}$ el caso que se expone se formularon cuestionamientos en torno de la forma de establecer una investigación colaborativa, de manera que, en el acompañamiento etnográfico y durante el proceso de la investigación se observaron categorías que fue necesario discutir para propiciar un diálogo intercultural, e inclusivo, con los colectivos señalados, y tomando en cuenta cada contexto histórico particular. En este caso nos percatamos de que existía una limitante, la de que el proyecto de la investigación colaborativa procede y se enmarca en el trabajo planteado por las investigadoras desde la instancia de dos instituciones

18 "Viento, Tierra, Sol, Agua", los cuatro elementos de la vida. diócesis.

19 Grupos de indígenas del Estado de Tabasco y Chiapas, que correspondían a la misma

20 A decir de Clifford Geertz (1994:202), quien aplica este método a estudios de derecho: "En suma, no es lo que sucedió, sino lo que sucede, lo que el derecho observa; y si el derecho difiere de un lugar a otro, de una época a otra, de un pueblo a otro, lo que este observa también lo hace" 
académicas, ECOSUR y AECID ${ }^{21}$, que aunque podían estar comprometidas con el desarrollo comunitario, se requería de un tiempo para confiar en una postura integradora.

Para analizar cómo se vive la intervención comunitaria a la vez que apostar por otras formas de acción investigativa, nos fuimos preguntando: ¿cómo se entiende la intervención comunitaria? Hay diferentes formas de entender la intervención, unas más implicadas en las acciones de las instituciones gubernamentales y políticas públicas, otras más en atender la idiosincrasia de cada organización, en culturas privadas y comunitarias del momento histórico y, por último, una perspectiva de índole religioso y espiritual.

\subsubsection{Metodologías de intervención e investigación}

Las metodologías desarrolladas responden a una etnografía reflexiva donde cobra protagonismo el proceso en sí, las estadías en las comunidades y colectivos desde donde se parte, las conversaciones, grupos de discusión, conferencias, participaciones en congreso (colaborativos) y talleres, llevados a cabo durante dos años.

El análisis parte de cómo integrar el área de estudio, sus participantes y quienes investigan meta reflexivamente y a la vez cuestionar las direcciones desde donde se teoriza. En el siguiente cuadro se sistematiza cómo ha estado dirigido el conocimiento mediante una metodología sistémica que va desde las intenciones investigativas y su desarrollo dentro y fuera de las comunidades de estudio, con un enfoque emancipatorio ${ }^{22}$ a la vez que en el reconocimiento de la resiliencia que se obtiene en el proceso de identificar colaborativamente potencialidades y dificultades de los colectivos junto a su propio historicismo. Es un proceso que perdura en el tiempo y que como un sistema, todo está interrelacionado, las emociones (ilusiones y desilusiones) que se comparten como las dificultades en las demandas políticas y los poderes estructurales, donde el propio investigador se hace alarde de la situación, tomando partido de las decisiones que va tomando la comunidad, a veces en una confusión de roles entre investigador e investiga-

${ }^{21}$ ECOSUR (El Colegio de la Frontera Sur) tiene un prestigio conseguido en pro del desarrollo comunitario, pero sigue siendo una institución pública y académica que no siempre está enmarcada en una horizontalidad con las poblaciones donde realiza sus investigaciones. La AECID (Agencia Española de Cooperación Internacional) no es del todo conocida por las comunidades y no fue limitante para el trabajo colaborativo. En cambio, al ser española y antropóloga una de las investigadoras se requirió de tiempo para obtener confianza y realizar el trabajo de campo, sobre todo en la Pastoral social indígena, debido a la represión desde el movimiento zapatista (etnografía con Ik'naskhinjha)

22 Este enfoque tiene como objetivo facilitar autonomía, encontrar potencialidades y a la vez empoderamiento tanto del colectivo como de sus integrantes. Tiene un carácter político potenciado desde una educación al desarrollo, y en sí, es dar visibilidad a procesos emancipatorios que se están dando y fortalecen la transformación social y el desarrollo comunitario. 
dos, siendo esto parte del objetivo del acompañamiento al colectivo como de la investigación.

\section{Cuadro 5. Dinámicas metodológicas-teóricas de la etnografía reflexiva en procesos emancipatorios.}

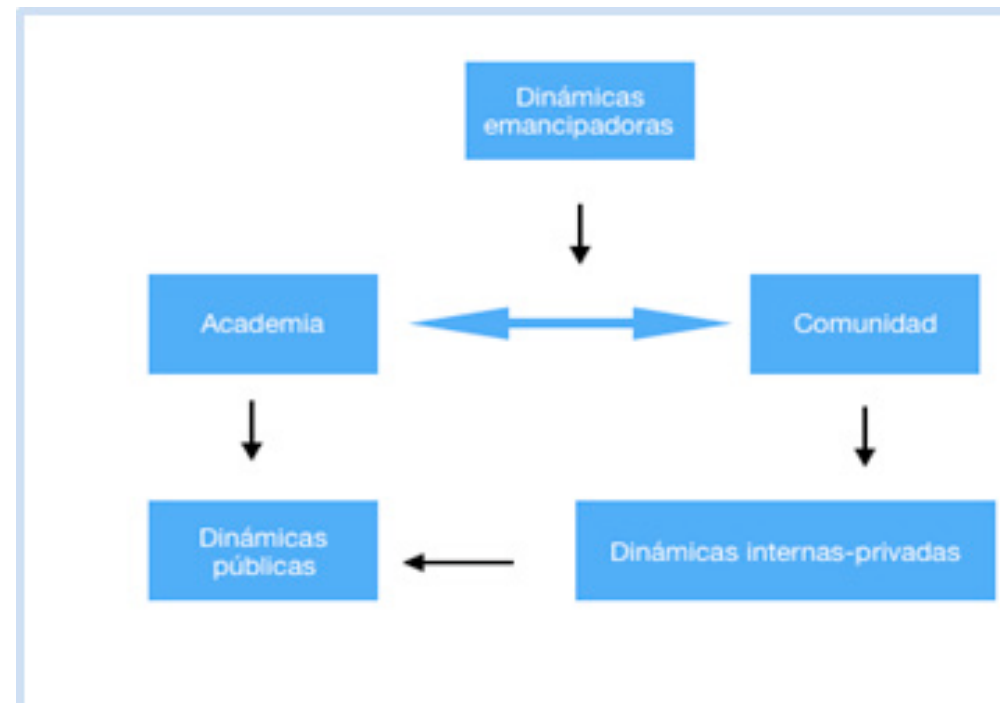

La metodología aplicada circula desde la etnografía, se realizaron talleres reflexivos, entrevistas, pasantías y conversaciones en las comunidades de estudio. Estas dinámicas favorecen la confianza y el entendimiento de sus propios procesos, pero el vínculo con la investigación se apropiaba de una militancia por mejorar y apoyar en la emancipación de sus colectivos, cuya valoración no será en este artículo, pero reconocemos parte de la identificación de procesos reflexivos emancipatorios. Se reconocieron desde lo privado (más personal) y lo público (comunitario), conceptos del deseo y la identidad, además de unificar los procesos colaborativos y las relaciones que se crearon a partir de estos encuentros.

\subsubsection{Resultados en Intervenciones coloniales y des-intervenciones descoloniales}

Desde nuestra interpretación en el acompañamiento en campo, se había planteado cuestionar las formas en que se producían los procesos de colaboración y en su caso de intervención en las comunidades estudiadas. En el cuadro 6 se muestran de manera sintetizada las respuestas a los cuestionamientos formulados, y las anotaciones se vinculan de manera importante con la experiencia que tienen las organizaciones con la intervención gubernamental. El objetivo fue profundizar en posturas sobre cómo veían las participaciones de ONG e insti- 
tuciones (universidades y gobierno), lo que pasaba al respecto en el campo, sin perder de vista la presencia misma del investigador, que a la vez, forma parte de investigador y activista dentro de los escenarios que se presentan.

Consideramos que son intervenciones por la relación, colaborativa y no, pero con un tinte de la perspectiva colonial que se presenta. Se configura desde la experiencia cotidiana y las relaciones que se mantienen con agentes de desarrollo y diferentes intervenciones gubernamentales y no gubernamentales. para situar significados en cuanto a una participación democr: actores protagonistas del cambio.

Cuadro 2. Intervenciones coloniales y des-intervenciones descoloniales.

Mujeres artesanas yokotan'ab chontales de Tapotzingo
Centro de estudios superior bilingüe: Centro Tecnológico de Buena Vista I, de Tamulté de la Sabana

\section{Intervención colonial y postcolonial}

-Utilitarismo de mujeres organizadas para darle proyectos productivos inoperativos por el empeño de técnicos e instituciones, asimilación de una cultura capitalista. -Asistencialismo de voluntariado que juzga sus prácticas y modos de vida.
Cómo sería una intervención comunitarias a manera de Des-intervención colaboración Des-colonial

-Apoyo en proyectos productivos de artesanía.

- Sin prisas "institucionales" ("proyectitis-parches") -Escucha de la comunidad. -Respeto por usos y costumbres.

-Compartir sus comidas y fiestas y jornadas diarias con los agentes comunitarios (privado y público).

- Sistema de mercado justo. -Contestar sinceramente a ¿cómo lo ves? ¿lo entiendes? ¿Quién lo ve

-Asistencialismo del bilingüismo y críticas de la resistencia.

-Clientelismo de partidos políticos.

-Discriminación positiva.
-Ser bilingües y promocionar patrimonio de la humanidad. -Participar los agentes en las resistencias comunitarias. -El equipo directivo debe estar implicado en la apuesta política del centro.

-Crear libros de primaria y secundaria en yokot' an (idioma indígena).

-No esencializar la cultura indígena.

- Vincular la educación al desarrollo comunitario. 


\section{Intervención colonial y postcolonial}

Asociación de Pescadores de La Barra de San Pedro y mujeres filateadoras de pescado.

\begin{abstract}
-Asistencialismo con ayudas de Pemex para limpiar el concepto de "ecoterroristas."

-Utilización de la universidad para conocer la cultura y modo de vida del pescador: conocimiento científico "interesado". -Caracterización como "hombres viciosos.
\end{abstract}

\section{Cómo sería una intervención comunitarias a manera de Des-intervención - colaboración Des-colonial}

-Permisos para participar en proyectos públicos-privadosacadémicos.

-Inclusión de pescadores en los comités de desarrollo.

-Favorecer leyes para hacer asociaciones y cooperativas. -Participar en los foros políticos y universitarios sobre sostenibilidad de la pesca.

-Dejar que el sector pesquero elija cómo quieren organizar su modo de vida (cooperativa, asociación, pesca artesanal y no industrial o de piscifactoría).
-Desacreditar las creencias mayas.
-No ser considerados en la Universidad Intercultural, desacreditación de la cul- tura maya.
-Relacionar su resistencia con el movimiento za- patista y ser condenado su activismo.

-Inculturación maya en prácticas de la religión católica.

-Trabajo del perdón por la historia colonial favorece la inclusión de no indígenas en sus políticas de resistencia.

-Compartir sus reuniones: escuchar, entender sus creencias como transformadoras y anticapitalistas.

-No hacer públicas sus demandas por peligro.

-Trabajo de reencuentro con sus antepasados.

De este resumen, destacamos algunas de las intervenciones que consideramos que requieren de visibilizarse. En muchas ocasiones existen necesidades de crear proyectos de desarrollo y denominamos "proyectiles" a los aspectos que muestran que no hay un interés cercano por la realidad de cada escenario. Es el caso de los proyectos productivos del gobierno de hacer un traspatio con hortalizas y posteriormente un comedor. Los intereses comunitarios no fueron en ningún momento analizados y se incluyó a un hombre discordante del grupo de mujeres a quienes iba destinado primordialmente el proyecto, lo que hizo que se dividiera el grupo, y además, parece ser que el objetivo estaba marcado únicamente por cumplir con una partida económica sobre desarrollo sustentable y que se visibilizara, en este caso surge de SERNAPAM (Secretaría del Estado 
de Tabasco, México: Secretaría de Energía, Recursos Naturales y Protección Ambiental) y sus objetivos no respondieron a las necesidades de las mujeres artesanas, así que el proyecto no fue duradero y fracasó.

Estas acciones se complementan con las necesidades de un asistencialismo que surge de alguna manera desde la toma de conciencia y de un "sentimiento de culpa". Se observaron las necesidades de personas "supuestamente con valores de solidaridad", de entornos petroleros, que parecen estados para "lavar conciencias", a la vez que la mirada superpuesta en los modos de vida de la población indígena, se expresa en términos como: "se deja llevar por su marido, se gasta el dinero que le he dado en la fiesta de cumpleaños de su hija", "no les gusta trabajar en el huerto" (comentarios de técnicos de PEMEX, que participaban como voluntarios de proyectos de desarrollo).

A esto sumamos complicadas actuaciones de la universidad con el sector pesquero, "subalternizado" ya que no quieren ver al pescador en el entorno académico: "el pescador debe estar en su lugar de trabajo" (indicó un biólogo de Tabasco - ECOSUR), ¿por qué la academia puede ir a las comunidades y no hacer este viraje para acercar lo empírico a lo teórico?. Aquí el empeño por transformar está en base de actitudes sobre el encuentro y el diálogo de saberes, pero aún siguen existiendo instituciones que desde arriba no se acercan a lo local, sino solo desde su única perspectiva.

En cuanto a la Red Municipalista de mujeres, se trabajó directamente en un acompañamiento donde diversos feminismos entre hombres y mujeres se manifestaban en una constante reflexión y empoderamiento con independencia de los poderes estatales, en la lucha para el reconocimiento de las resiliencias de mujeres en terrenos con explotaciones petroleras así como en el apoyo a mujeres que sufren violencia de género (Muñoz, 2014), protagonizaron el proceso de llevar al congreso la Ley de Acceso de las Mujeres a una Vida Libre de Violencia ${ }^{23}$. Consideramos que este colectivo es protagonizado por mujeres que se mueven desde la experiencia en la resistencia, enfatizado por vivir en zonas afectadas de la Chontalpa y otras que han sufrido violencia de género. Su autonomía favorece un trabajo colaborativo.

Por último destacamos la perspectiva de Ik'naskinjha donde el trabajo colaborativo fue llevado desde tres fases: primero fue la desconfianza en la investigación por ser parte de una academia colonizadora; segundo el trabajo colaborativo, el acercamiento de la investigadora a la realidad y a sus vidas, el acompañamiento en las reuniones y tomas de decisiones y; en tercer lugar el perdón del proceso colonial producido en su historia la propia investigadora. Estas fases replantean otra forma de hacer conocimiento desde la conciencia del historicismo vivido por la pastoral indígena.

Este caso, como ya se dijo, se trataba de establecer una ruta crítica colaborativa, que posteriormente implicara los conocimientos de los actores y cuyo acompañamiento aspirara a que la investigación aportara a comprender la des-

${ }^{23}$ Tabasco: OSC presentan iniciativa de Ley para Vida sin Violencia. Por: Cecilia Vargas/ corresponsal.

EMPIRIA. Revista de Metodología de Ciencias Sociales. N. ${ }^{4} 4$ septiembre-diciembre, 2019, pp. $179-211$.

ISSN: 1139-5737, DOI/ empiria.43.2019.25356 
igualdad e injusticia social que estaban viviendo algunos colectivos de Tabasco. De manera similar al primer caso en Oaxaca, observamos que está presente el autoritarismo, la exclusión social, la discriminación y la injusticia forman parte de contexto político social. Esto nos muestra una lógica de actuación en las instituciones gubernamentales de forma general, cuyo eje es su ejercicio autoritario a través de dispositivos institucionales instaurados en los programas asistencialistas y clientelares. La integración (inclusión social a través de los programas) de las comunidades cae en la relación colonial, en la que aparecen estructuras patriarcales del Estado que acoge a poblaciones más vulnerables y las "obliga" a "adaptarse o morir" (Muñoz y Álvarez, 2015:154).

La dimensión institucional de la que se habla y su cuestionamiento también obliga a identificar las dimensiones psicológicas/emocionales que muestran desesperación, desesperanza e indignación ante el autoritarismo institucional. Al respecto Soussa (2015:139) sugiere considerar la reformulación de la subjetividad la investigación "como algo que va más allá de la cuestión de la metodología de la investigación (...) a prestar atención a la relación que existe entre la acción social y el conocimiento social inherente a la movilización proactiva y reactiva".

\section{LOS DOS CASOS}

Enlazando los casos expuestos en Oaxaca y Tabasco, se muestra una lógica de actuación autoritaria de las instituciones y autoridades de gobierno. Como parte del ejercicio reflexivo de intervención - colaboración es necesario comprender cómo se sostiene la lógica clientelar y autoritaria dentro de los espacios, así como la forma en que la sociedad se articula a ella, normalizando esta relación. Este entendimiento emerge del diálogo intercultural que vincula por una parte la experiencia de la ciudadanía con el ejercicio de las leyes, y por otra parte la construcción de leyes por los grupos de poder gubernamental y la operación institucional cuyas formas políticas y culturales forman parte de la conformación de la ciudadanía inmersa en la opresión, autoritarismo y corrupción y que a la vez se alimenta de estas prácticas para reproducirlas a diferentes escalas y cuyo resultado es un tejido social quebrantado. La desconfianza, el individualismo, así como la resiliencia y la lucha a favor del pluralismo y la democracia forman parte de las dinámicas paradójicas.

Una forma de entender las lógicas de operación de Ley es el modelo de la abogada Alda Facio (1992:65), ella menciona que el fenómeno jurídico tiene tres ámbitos principales: la ley como texto normativo (componente formal); la estructura operativa (componente estructural) y la cultura ciudadana (componente cultural). Con respecto al primer ámbito, para que las leyes existan y sean reconocidas como tales, tienen que estar escritas y formalmente promulgadas. En el caso de Oaxaca la Constitución Política de los Estados Unidos Mexicanos, en su artículo 115, establece disposiciones para que los municipios administren libremente su hacienda y la Ley de Coordinación Fiscal establece la distribución de recursos públicos en siete Fondos de aportaciones a los municipios para 
que estos se distribuyan de acuerdo a las reglamentaciones, entre otras leyes de carácter regulatorio. Tanto el segundo como el tercer ámbito conforman puntos críticos ya que, como mencionamos antes, "lo jurídico no solo es la ley".

Existe una interrelación entre los tres componentes mencionados, de tal manera que podemos observar como un componente incide sobre otro. Por ejemplo, del componente cultural al componente normativo, Facio (1992:67) menciona:

"el componente político cultural determina el contenido del componente formal-normativo (...) quienes hacen las leyes son personas de carne y hueso que están impregnadas de actitudes, juicios y preconceptos con respecto a las personas a quienes va dirigidas, especialmente cuando esas personas pertenecen al sexo femenino, a una raza/etnia discriminada, a un grupo minoritario, etc."

Siguiendo con el caso de Oaxaca, en el segundo ámbito, la estructura operativa, el cual hace referencia a la estructura en la que opera la ley, establece los mecanismos para que los Fondos de aportaciones a municipios se operen a través de los gobiernos estatales de cada entidad federativa, es decir a la operación directa de instituciones y personas que dan ejecución a las acciones descritas en la $\mathrm{Ley}^{24}$. Es importante decir que los operadores de las leyes dan significados e interpretan los alcances que tienen las leyes e incluso existe un margen en el uso del poder que se otorga a las personas que ejecutan estas acciones. Es aquí uno de los puntos en el que el eslabón de la Ley se distorsiona, si bien el gobierno estatal tendría que ser un ejecutor de la Ley, la forma en que se otorgan los recursos se vincula a las relaciones directas que tienen los presidentes municipales (como autoridades locales) con el gobernador. En este sentido, las filiaciones partidarias y los pactos políticos se relacionan directamente con las administraciones oportunas de los gobiernos locales e incluso con el otorgamiento de "recursos extraordinarios" que pasan por negociaciones discrecionales ${ }^{25}$. $\mathrm{Al}$ respecto hay "huecos en la ley o en las reglamentaciones" que toleran estas

24 Además de lo establecido en el artículo 115 en la Constitución mexicana, a nivel federal se establecen normatividades al respecto en Ley de Coordinación Fiscal; Código Fiscal de la Federación; Ley del Impuesto Sobre la Renta; Ley del Impuesto al Valor Agregado; Ley de Ingresos de la Federación; Presupuesto de Egresos de la Federación; Manual para la Fiscalización de los Recursos del Ramo 33; Lineamientos para el reporte del ejercicio de los Recursos del Fondo de Aportaciones para la Infraestructura Social Municipal; y las leyes estatales relativas por cada entidad federativa

${ }^{25}$ La prensa mexicana ha documentado numerosos casos de manifestaciones de gobiernos locales por el corte de recursos públicos de manera autoritaria, así también se ha detectado el uso discrecional y politizado que se da a los recursos públicos. Otro ejemplo respecto al ejercicio de recursos públicos es el Fondo del Ramo 23 de los que no hay rendición de cuentas, así como el mal funcionamiento de los Fondos Metropolitano y Regional, para mayor referencia véase Iracheta, A1fonso y José A. Iracheta (2014). Evaluación de los Fondos Metropolitano y Regional del Gobierno Federal Mexicano. México, CIDE. Y consulte notas de prensa https://www.animalpolitico.com/ blogueros-el-blog-de-mexico-evalua/2014/11/12/regular-el-ramo-23-mas-responsabilidad-menosdiscrecionalidad/\#_ftn2 
acciones o dan margen a los gobiernos locales para politizar el otorgamiento de recursos públicos.

El tercer componente refiere a la construcción histórica de la ciudadanía, en este caso a la experiencia ciudadana en la socialización de la norma y su aplicación cotidiana. Este elemento sin duda juega un papel importante y es parte fundamental de las reflexiones. Las experiencias de exclusión por género, clase social, origen étnico, pertenencia a grupos políticos (diferentes al dominante), forman parte de la experiencia del ejercicio ciudadano al intentar acceder a recursos y servicios públicos.

El caso de Tabasco nos muestra una ciudadanía activa, organizada en varios colectivos que responden a las necesidades de una región transformada de manera implacable por la explotación de petróleo y por procesos políticos y económicos complejos que se conectan a nivel nacional y mundial, todos ellos relacionados con la protección del mercado y el mantenimiento de la paz social en las zonas de explotación de recursos. Sin embargo, el autoritarismo y la corrupción han sido dos constantes que se mantienen como formas de hacer política en el país. Reanudando las reflexiones de Facio, las leyes en México pueden proyectar hacia el exterior cambio democrático; sin embargo todas ellas pueden ser letra muerta, mientras a nivel operativo no se llevan a cabo o reproduzcan las mismas prácticas políticas o de impunidad. En el caso de Tabasco, los procesos de modernización han tratado de soslayar los idiomas regionales, las prácticas de pesca tradicionales se han paralizado por los fenómenos de contaminación. $\mathrm{Al}$ inicio del siglo XXI, se inaguraron leyes e Instituciones para la transparencia de recursos públicos; para la consulta de los pueblos en caso de instauración de mega proyectos; se modificaron las normativas para obtener recursos públicos (Reglas de Operación); se instauraron mecanismos para promover las lenguas indígenas en el país; y la lista podría seguir, todos estos cambios supondrían el mejoramiento de las condiciones de vida del conjunto pluridiverso de poblaciones en el país, equidad social y garantía sobre derechos ciudadanos en el país. Empero, la realidad es más compleja y adversa; en tanto es necesario luchar por el respeto de la ley, por el cambio cultural de quienes operan la ley y de los ciudadanos que se favorecen de ellos. Significa redefinir la ciudadanía, darle sentido de acuerdo a la diversidad de proyectos en agendas de lucha común.

En lo que va del siglo XXI, la participación ciudadana ha crecido, no de manera suficiente, pero existen resistencias, oposiciones y disidencias que de manera insistente promueven encuentros para realizar agendas ciudadanas y municipales ${ }^{26}$, participativas que consideraran las luchas indígenas, de género, de sectores productivos entre varias identidades colectivas.

${ }^{26}$ Véase Rodríguez, C. (2008): "La agenda ciudadana municipalista y la reforma del Estado" en Política y Cultura, primavera, núm 29, pp. 71-97; De Mauleón, H. (2012):“\#YoSoy132 y el uso político de las redes sociales" en Revista Nexos, Núm. 417, p. 34-42; Kuri, E. (2010) "El movimiento social de Atenco: experiencia y construcción de sentido en Andamios. Revista de Investigación Social, vol. 7, núm. 14, septiembre-diciembre, pp. 321-345; Martínez R. (2015): "La construcción de presas como manifestación del despojo extractivista y la defensa de los territorios como estrategia de resistencia de las comunidades Velarde", en Entretextos, año 6, número 18, 


\section{CONCLUSIONES}

Si bien hay distintas formas de intervención social, en tanto no existe un método para todos los casos y adecuado para la historicidad de los grupos o personas, la intervención está marcada por los aspectos de intencionalidad y autoridad (Barriga 1987; Dubost, 1987 citado en Montero, 2012). Es claro que existe una relación de poder entre la intervención y el intervenido, en tanto que el conocimiento institucional se antepone y se aplica de manera directiva. Los actores que participan en el proceso no parten de referentes de conocimiento similares y las herramientas con las que se resuelve las problemáticas la mayor parte de las ocasiones emergen de los conocimientos de los agentes externos: instituciones de Estado; organizaciones no gubernamentales, sociedad civil, organizaciones de desarrollo, entre otros.

En ambos casos expuestos en este trabajo están presentes las tensiones asociadas a las relaciones asimétricas: en ocasiones se lidia con estas de manera más productiva que otras. Lo evidente en la experiencia de trabajo, e incluso en la propia experiencia personal, es la desconfianza en la Ley y sus instituciones. Sin embargo, como nos lo muestra Facio, el proceso es más complejo, en tanto el contexto cultural de aplicación y su operación por las instituciones son desafíos sobre los que reflexionar para generar acciones a la par.

La experiencia de campo aquí expuesta hizo énfasis especial en la incorporación de los derechos humanos y la comprensión de las herramientas legales y su operación en los contextos de intervención comunitaria. La defensa de los derechos, si bien apela a la integración de la universalidad de los mismos, acercándose a la concepción de un "nosotros", en la cotidianidad institucional se establece la condición de los "otros" excluidos, exigentes de esos derechos, cuyas carencias y diferencias se distancian de los modelos de ciudadanía deseables y en muchos casos la situación social y falta de herramientas jurídicas los coloca en una situación de indefensión.

La intención de documentar y analizar los casos aquí presentados responde a la necesidad de reflexionar sobre la práctica en campo, cuestionarla, y esperamos también transformarla. De ello parte el objetivo de investigación militante. Y como se dijo antes, es necesario acoger epistemologías que provengan de las voces de los excluidos y marginados, así como documentar los procesos sociales mediante los cuales se conforma la ciudadanía, poniendo al centro actores y organizaciones colectivas.

Para ello confiamos en esta introspección de las actuaciones que trabajan por la justicia social, ya que es complicado evitar los universalismos y la rigidez que no solo está en el ámbito de las políticas institucionales y académicas, sino en organizaciones no gubernamentales, en asociaciones, en el voluntariado y organizaciones religiosas.

La experiencia investigativa y de intervención se favorece con una participación en el encuentro de los saberes comunitarios, reconocer las diversas

pp.1-12

EMPIRIA. Revista de Metodología de Ciencias Sociales. N. ${ }^{\circ} 44$ septiembre-diciembre, 2019, pp. 179-211.

ISSN: 1139-5737, DOI/ empiria.43.2019.25356 
identidades y visibilizarlas, que promuevan en sí transformaciones, y en su caso se requiere un estudio de las propias emancipaciones, dentro y fuera de sus estructuras, observar sus consecuencias y recordar las posibilidades de mantener un equilibrio en el espacio-tiempo. Además, una metodología en acción y transformadora puede ayudar a promover la resiliencia de los colectivos, promocionando la evaluación de los procesos donde existe la intervención, tanto de sus participantes como de los agentes movilizadores. Entendiendo que los balances de poder varían de acuerdo con el contexto y situación examinada, sin embargo; es innegable la relación de poder que ejerce el investigador en la dirección de lo que es su interés investigar y la difusión que dará al conocimiento que se produce. El desequilibrio del poder que se experimenta en la intervención, por más transformadora que se desee puede tener efectos negativos para los sujetos, quienes en la mayor parte de las ocasiones no dominan la esfera académica.

\section{BIBLIOGRAFÍA}

ALMOND, G.A. y SIDNEY, V. (1989): The Civic Culture. Political attitudes and democracy in five nations, Newbury Parke, Sage.

ÁlVAREZ, G. C., \& TUÑóN, E. T. (2016): "Vulnerabilidad social de la población desplazada ambiental por las inundaciones de 2007 en Tabasco (México)", Cuadernos de Geografía: Revista Colombiana de Geografía, 25(1), pp.123-138.

BUSTILLOS, G. y VARGAS, L. (1993): Técnicas participativas para la educación popular, tomo 2. IMDEC, México.

BRIONES, C., (2005): "Formaciones de la alteridad: contextos globales, procesos nacionales y provinciales", en Cartografías argentinas: políticas indígenas y formaciones provinciales de la alteridad, Buenos Aires, Argentina, Antropofagia.

CDI Comisión Nacional para el Desarrollo de los Pueblos Indígenas (2015): Sistema de indicadores sobre la población indígena de México, México.

CEDEÑA DEL OLMO, M. (1995): "Las elecciones en Tabasco y la pugna por la gubernatura, 1988-1994: los nudos de la transición regional”, Revista Mexicana de Ciencias Políticas y Sociales, 40(161), pp.161-182.

CLIFFORD, G. (1994): Conocimiento local: ensayos sobre la interpretación de las culturas, Barcelona, Bueno Aires, México, Paidós.

DIETZ, G. (2012): "Reflexividad y diálogo en etnografía colaborativa: el acompañamiento etnográfico de una institución educativa intercultural", Revista de Antropología social, 21, pp.63-91.

ENCUESTA INTERCENSAL 2015. Principales resultados. Instituto Nacional de Estadística y Geografía, México. Disponible en: http://internet.contenidos.inegi.org.mx/ contenidos/productos/prod_serv/contenidos/espanol/bvinegi/productos/nueva_estruc/702825078966.pdf

FACIO, A. (1992): Cuando el género suena cambios trae (una metodología para el análisis de género del fenómeno legal), San José, C.R., ILANUD.

GARCÍA, M. (2014): Derecho a falta de democracia, Análisis político no. 82, pp.167195. 
GRACIA, J. y FUENTES, O. A. (2005): "La problemática del agua en Tabasco: inundaciones y su control", en El agua en México vista desde la academia, México, UNAM, pp.177-187.

GUTIÉRREZ, S. (2007): "La construcción de la imagen de López Obrador en los spots de sus adversarios", Cultura y representaciones sociales, 1(2), pp. 31-54.

HALE, Ch. (2008): La antropología comprometida en transición, en Multiculturalismo y futuro en Guatemala, Guatemala, FLACSO/OXFAM, pp. 217-245.

IRACHETA, A. y IRACHETA, J. A. (2014): Evaluación de los Fondos Metropolitano y Regional del Gobierno Federal Mexicano, México, CIDE.

LARA, G. (2007): "El recurso de la diferencia étnico racial en las lógicas de inclusión política. El caso de Pinotepa Nacional, Oaxaca" Los retos de la diferencia. Los actores de la multiculturalidad entre México y Colombia, CEMCA, CIESAS, IRD, México, pp. 81-110.

LARA, G. (2012): Espacios, sociedades y acción institucional en la Costa de Oaxaca, CONACULTA, Fundación Harp-Helú, Gobierno del Estado de Oaxaca, Colección de las Antiguas Raíces.

LARA, G. (2018): Elecciones y alternancia en la Costa de Oaxaca al inicio del siglo XXI Gloria Lara Millán. México: Facultad de Historia, Universidad Michoacana de San Nicolás de Hidalgo.

LEYVA, X. y SPEED, S. (2008): "Hacia la investigación descolonizada: nuestra experiencia de co-labor", en Gobernar (en) la diversidad: experiencias indígenas desde América Latina. Hacia la investigación de co-labor, México, Publicaciones de la Casa Chata, Ciesas, Flacso, pp. 65-107.

LEWIN, K. (2006): "La investigación-acción y los problemas de las minorías", en La Investigación-Acción Participativa, inicios y desarrollos, Madrid, Editorial popular, pp. $15-25$

LUGONES, M. (2008): “Colonialidad y Género: Hacia un feminismo descolonial”, en Género y Descolonialidad. Buenos Aires, Del Signo, pp. 13-54.

LACLAU, E. (1985): "New social movements and the plurality of the social", in New Social Movements and the State in Latin America, Amsterdam, Centro de Estudios y Documentación Latinoamericana, pp. 27-42.

NAVARRETE, J. P. (2016): "Tipología del liderazgo en el Partido de la Revolución Democrática (PRD), 1989-2015”, Revista de El Colegio de San Luis, 6(12), pp.74114.

MONTERO, M. (2012): "El Concepto de Intervención Social desde una Perspectiva Psicológico- Comunitaria" en Revista MEC-EDUPAZ, Universidad Nacional Autónoma de México, I, pp. 54-76.

MORENO, M. A. (2013): "Psicoanálisis e intervención social”, CS, N. 11, pp. 115-142.

MUÑOZ, G. (2015): "Imperialismo profesional y trabajo social en América Latina", Polis, Revista Latinoamericana, 14(40), pp. 421-438

MUÑOZ, P. (2012): "Etnografía sobre políticas públicas y cotidianidad a partir de pescadores y pescadoras en Tabasco y Chiapas, "políticas que apoyan a la subalternidad”, en La pesca: un solo espacio, diferentes enfoques de estudio, México, Universidad Autónoma de Guerrero, pp. 69-86

MUÑOZ, P. (2014): "Experiencias de construcción de antropologia e identidades de género en colectivos de mujeres en Tabasco. Dilemas de la antropologia comprometida. ¿Cambios posibles?”, en Democracia, cultura política y ciudadanía en el México de hoy, México, UNAM, pp. 175-197. 
MUÑOZ, P. (2016): “(De)construcción de un estado utilitarista a partir de organizaciones del pueblo indígena en Tabasco, México, yokot'an, chol y zoque: educación política", Trama, revista electrónica de ciencias sociales, 5, pp. 7-20.

MUNOZ, P. y ÁLVAREZ, M. (2015): "La escucha etnográfica en la violencia de género desde espacios educativos culturales. Reflexión para descolonizar el feminismo", en Feminismo/s, 25. Disponible en: http://dx.doi.org/10.14198/fem.2015.25.08 [consulta 20-02- 2018].

MUÑOZ, P. y CRUZ J. L. (2013): "Identidades y tendencias migratorias desde la pesca en Chiapas y Tabasco", Convergencia. Revista de Ciencias Sociales, 63, pp. 231257.

PINKUS, M. J., y CONTRERA, A. (2012): "Impacto socioambiental de la industria petrolera en Tabasco: el caso de la Chontalpa", LiminaR, 10(2), pp.122-144.

RAPPAPORT, J. y RAMOS, A. (2005): Una historia colaborativa: retos para el diálogo indígena- académico", en Historia Crítica, núm. 29, Universidad de Los Andes, Bogotá, Colombia, pp. 39-62.

REYGADAS, L. (2014): «Todos somos etnógrafos, igualdad y poder en la construcción del conocimiento antropológico» en La etnografía y el trabajo de campo en las ciencias sociales, Universidad Nacional Autónoma de México, Instituto de investigaciones Antropológicas, pp. 91-118.

RIVERA, O. (2011): "El Partido (partido) de la Revolución ¿Democrática? La dominación carismática en el PRD”, Espacios Públicos, 14(32), pp. 152-182.

ROBERTSON, R. (1992): Globalization. Social Theory and Global Culture, Londres, Sage.

SANTOS, M. A., (2012): "Derechos humanos: compromisos internacionales, obligaciones nacionales" en Revista Mexicana de Justicia, Instituto de Investigaciones Jurídicas, UNAM, No. 12, disponible en línea: https://revistas.juridicas.unam.mx/index. php/reforma-judicial/article/view/8735/10770

SOUSA, B. D. (2010): Descolonizar el saber, reinventar el poder. Montevideo, Trilce, Extensión Universitaria.

SOUSA, B. D. (2011): "Epistemologías del sur", en Utopía y praxis latinoamericana, 16(54), pp. 17-39.

SOUSA, B. D. (2014): Si Dios fuese un activista de los derechos humanos, Madrid, Editorial Trota.

SPEED, S. (2006): "Entre la antropología y los derechos humanos. Hacia una investigación activista y comprometida críticamente" en Alteridades 16(31), pp. 73-85.

SUÁREZ, L. y HERNÁNDEZ, R. A. (2008): Descolonizando el feminismo. Teorías y prácticas desde los márgenes, Madrid, Cátedra.

TUDELA, F. (1992): La modernización forzada del trópico: El caso de Tabasco, Proyecto Integrado del Golfo, México, El Colegio de México, CINVESTAV, IFIAS Y UNRISD.

URIBE, R. (2003): La transición entre el desarrollismo y la globalización: ensamblando Tabasco, México, UNAM, CRIM.

VELÁZQUEZ, M. G. (1982): “Afectaciones petroleras en Tabasco: El movimiento del Pacto Ribereño", Revista Mexicana de Sociología, 44(1), pp. 167-187

VILLALÓN, A. M. (2012): "Reflexiones sobre la intervención social antropológica", Revista de Antropología Experimental, 12, Monográfico: Antropología en España: Nuevos Caminos Profesionales. Texto 7, pp. 103-114, Disponible en http://revista. ujaen.es/huesped/rae/articulos2012/MP07_12.pdf [consulta 20-02- 2018]. 
VITÓN, M. J. (2013): Diálogos con Raquel. Praxis Pedagógicas y reflexión de saberes para el desarrollo educativo en la diversidad cultural, Madrid: Editorial Popular.

WALSH, C. (2005): "Interculturalidad, conocimientos y decolonialidad", en Signo y pensamiento, Facultad de Comunicación y Lenguaje de la Pontificia Universidad Javerian, 46, Volumen XXIV, enero, junio, pp.39-50.

WIESENFELD, E. (2014): "La Psicología Social Comunitaria en América Latina: ¿Consolidación o crisis?", Psicoperspectivas, Individuo y Sociedad, 13(2), pp. 6-18.

ZALIK, A. (2009): "Zones of Exclusion: Offshore Extraction, the Contestation of Space and Physical Displacement in the Nigerian Delta and the Mexican Gulf", Antípode, 41(3), pp. 517-582. 
